\title{
Study of clinical profile and outcomes of Percutaneous Coronary Intervention in ST Elevation Myocardial Infraction.
}

\author{
Parash Koirala', Ratna Mani Gajurel', Chandra Mani Poudel ${ }^{1}$, Hemant Shrestha ${ }^{1}$, Surya Devkota ${ }^{1}$, \\ Sanjeev Thapa', Shovit Thapa', Surya Pathak'
}

${ }^{1}$ Department of Cardiology, Manmohan Cardiothoracic Vascular and Transplant Centre, Kathmandu, Nepal.

Corresponding Author: Parash Koirala,

Department of Cardiology

Manmohan Cardiothoracic Vascular and Transplant Centre, Kathmandu, Nepal.

Address: TUTH Complex, Maharajgunj,Kathmandu, Nepal

Email: parashkoirala123@gmail.com

ORCID ID NO: 0000-0002-5112-2230

Cite this article as: Koirala P., Gajurel R. M., Paudel C. M., et al. Study of clinical profile and outcomes of Percutaneous Coronary Intervention in ST Elevation Myocardial Infraction. Nepalese Heart Journal 2019; Vol 16 (2), 53-57

Submission date: $3^{\text {rd }}$ September 2019

Accepted date: 6th November 2019

\section{Abstract}

Background and Aims: Percutaneous Coronary Intervention (PCI) is the preferred method of revascularization in Acute ST Elevation Myocardial Infarction (STEMI). Our aim was to study the clinical profile and outcomes of patients who underwent PCI for STEMI at tertiary cardiac centre of Nepal.

Methods: It is a retrospective, single centre study, performed at Tribhuvan University, Manmohan Cardiothoracic Vascular and Transplant Centre, Kathmandu, Nepal. All patients who underwent PCI for STEMI from November 2015 to July 2018 were enrolled in this study. All the data were collected from hospital registry and cath lab records.

Results: The Study showed that out of 232 patients who presented with STEMI, $74.5 \%$ were male with average age of 57.39 years. The mean time of presentation after onset of symptom/s was 17.5 hours. About $66 \%$ patients presented in less than 12 hours of symptoms onset, $21 \%$ presented at 12-24 hours of symptoms onset and $13 \%$ patients presented late. Primary PCI was done in $87 \%$ of patients. Almost all patients (98.2\%) underwent coronary artery stenting with drug eluting stents. Multivessel PCI during index procedure was done in 7 patients. TIMI III flow following PCI was achieved in $97 \%$ cases. Average LVEF at discharge was $44.73 \%$. There were 8 deaths, all after Primary PCI. In-hospital mortality rates for patients presenting with and without cardiogenic shock were $38.46 \%$ and $1.59 \%$ respectively. The overall mortality rate was $3.98 \%$. Conclusion: This study has reemphasized that PCI is effective in the management of STEMI cases in Nepal with improving mortality rates and decreasing complications. Minimizing the delayed presentation after the onset of symptoms should be one of the prime focuses for effective management of STEMI.

Keywords: Coronary Artery Disease, Percutaneous Intervention, ST elevation Myocardial infarction.

DOI:

https://doi.org/10.3126/njh.v16i2.26318

\section{Introduction}

Ischemic Heart Disease (IHD) is the leading cause of mortality and morbidiy in the world ${ }^{1}$. In Nepal, IHD was the number 1 killer in year 2017 and will most probably remain so for at least few years to come ${ }^{2}$. IHD may present as stable IHD or Acute coronary syndromes (ACS). Among the ACS, the mortality rate is highest for
ST Elevation Myocardial Infarction (STEMI) $)^{3}$. Primary Percutaneous Coronary Intervention has emerged as the therapy of choice in STEMI and selected cases of Non-ST Elevation Myocardial Infarction $(\mathrm{NSTEMI})^{4-8}$. As Percutaneous coronary intervention (PCI) enters its fourth decade of use, it is now the most commonly performed revascularization therapy worldwide. With the development of drugeluting stents, clinical outcomes have improved significantly.

(a) Nepalese Heart Journal. Nepalese Heart Journal retain copyright and works is simultaneously licensed under Creative Commons Attribution License CC - By 4.0 that allows others to share the work with an acknowledge of the work's authorship and initial publication in this journal

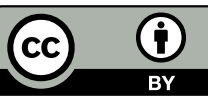




\section{Methods:}

It is a retrospective, single centre study, performed at Tribhuvan University, Manmohan Cardiothoracic Vascular and Transplant Centre, Kathmandu, Nepal. All patients who underwent PCI for STEMI from November 2015 to July 2018 were enrolled in this study. All the data were collected from hospital records and cath lab records. Two cardiac interventionists who were trained in interventional cardiology performed all procedures.

\section{Inclusion criteria:}

STEMI

Less than 12 hours

Cardiogenic shock or acute severe heart failure irrespective of time delay

Evidence of ongoing ischemia 12-24 hours after symptom onset

\section{Exclusion criteria:}

Patient who underwent thombolysis or medical management for STEMI and those who did not provide written consent.

All patients presenting with Acute STEMI were counseled about the treatment modalities in emergency (ER). As most of the patents now can afford Primary PCI under the coverage of funds provided by the Government of Nepal and our centre, and with clear outcome benefits of Primary PCI over thrombolysis, almost all patients presenting with STEMI were taken for Primary PCI if indicated. Those who did not give written informed consent for Primary PCI or chose medical management or thrombolysis were excluded from this study. Those patients presenting late were taken for elective PCI after hospital admission.

For Primary PCI, patients were given loading doses of Asprin (300 mg), Clopidogrel (600 mg) and Rosuvastatin $(20 \mathrm{mg})$ at ER. At cath lab, access for PCI was determined by the primary operator. Most of the cases were successfully performed via radial approach. Intravenous IV Unfractionated Heparin 10000 units was given after diagnostic CAG to maintain ACT of more than 300 seconds during procedure. Temporary pacemaker was inserted via femoral route whenever indicated. Thrombosuction was done in cases with high thrombus burden. Predilatation with a non complaint balloon was done for most of the cases followed by stenting. Only Drug Eluting Stents (DES) was used. In cases where stenting was not feasible, plain balloon angioplasty was done. Post dilatation with a non-compliant balloon was done as a routine unless stents were deployed with high pressure with no obvious unexpanded stent struts were visible. After PCI, all patients were transferred to cardiac care unit (CCU).

\section{Results}

Total of 232 patients meeting the inclusion criteria were included in the study from November 2015 to July 2018. The average age was 57.39 yrs with youngest patient being 24 years old and oldest being 86 years old. About 12\% (28) were less than 40 years of age. Most of the patients were male $(74.5 \%)$.

The commonest symptom was chest pain, present in $97 \%$ cases. The average time of presentation after symptom onset was 17.5 hours, earliest being 15 minutes.About $66 \%$ patients presented in less than 12 hours of symptoms onset, $21 \%$ presented $12-24$ hours of symptoms onset and $13 \%$ patients presented late. Among the traditional cardiovascular risk factors, smoking was the commonest. Nearly 50\% of the patients smoked while $35 \%$ were hypertensive, $28.2 \%$ diabetic, $2.6 \%$ had known dyslipidemia and 3.6\% had family history of MI.
Table 1: Baseline Characteristics, Diagnosis and Management Strategies

\begin{tabular}{|c|c|}
\hline Age (years) & $57.39 \pm 12.97$ \\
\hline \multicolumn{2}{|l|}{ Sex } \\
\hline Male & $173(74.5 \%)$ \\
\hline Female & $59(25.5 \%)$ \\
\hline Duration of symptom/s & $17.5 \mathrm{hrs}$ (15min-7days) \\
\hline Less than 12 hours & $153(66 \%)$ \\
\hline 12 to 24 hours & $49(21 \%)$ \\
\hline More than 24 hours & $30(13 \%)$ \\
\hline \multicolumn{2}{|l|}{ Risk factors } \\
\hline Diabetes Mellitus & $28.2 \%$ \\
\hline Hypertension & $35 \%$ \\
\hline Smoking & $50.4 \%$ \\
\hline Dyslipidemia & $2.6 \%$ \\
\hline Family h/o of CAD & $3.6 \%$ \\
\hline \multicolumn{2}{|l|}{ Presenting symptom/s: } \\
\hline Chest pain & $97 \%$ \\
\hline Shortness of breath & $20 \%$ \\
\hline Nausea/vomiting & $28 \%$ \\
\hline Abdominal pain & $7.5 \%$ \\
\hline Near syncope/syncope & $6 \%$ \\
\hline \multicolumn{2}{|l|}{ Killip class } \\
\hline Class I & $88.4 \%$ \\
\hline Class II & $5 \%$ \\
\hline Class III & $1 \%$ \\
\hline Class IV & $5.6 \%$ \\
\hline \multicolumn{2}{|l|}{ Diagnosis: } \\
\hline Anterior wall STEMI & $53 \%$ \\
\hline Inferior wall STEMI & $41.8 \%$ \\
\hline Posterior wall STEMI & $3.4 \%$ \\
\hline Lateral wall STEMI & $1.7 \%$ \\
\hline \multicolumn{2}{|l|}{ Procedure: } \\
\hline Primary PCI (PPCI) & $202(87 \%)$ \\
\hline Elective PCI & $30(13 \%)$ \\
\hline LVEF at discharge & $44.73 \%$ \\
\hline Duration of hospital stay (days) & 7.6 \\
\hline
\end{tabular}

$88.4 \%$ of patients presented in Killip class I while $5.6 \%$ patients presented in Killip class IV. Anterior wall STEMI was commonest accounting for 53\% followed by Inferior wall, $41.8 \%$.

Angiography revealed SVD in 35\%, DVD in 33.3\%, TVD in 29.1\%. Left Main Coronary Artery involvement was seen in 5 cases and 1 Left Main angioplasty was done. 
Fig -1: Diagnosis by Number of Vessels Involved

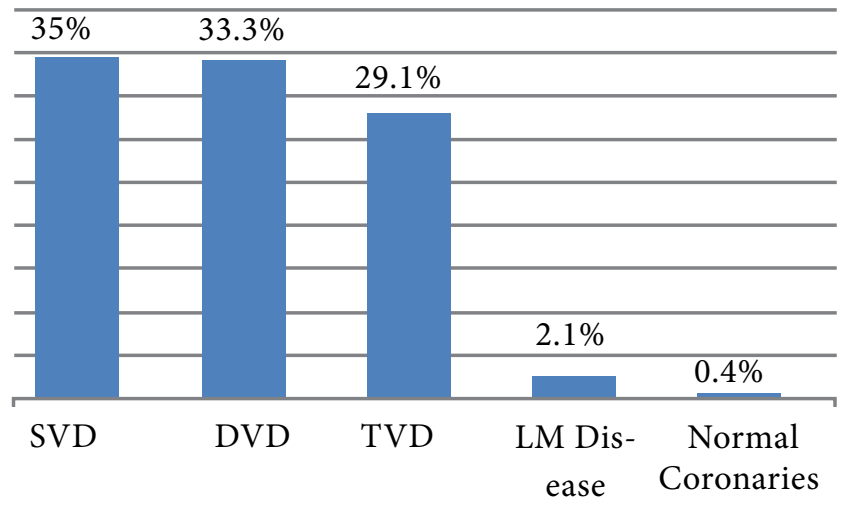

Fig -2: Culprit Vessel for STEMI

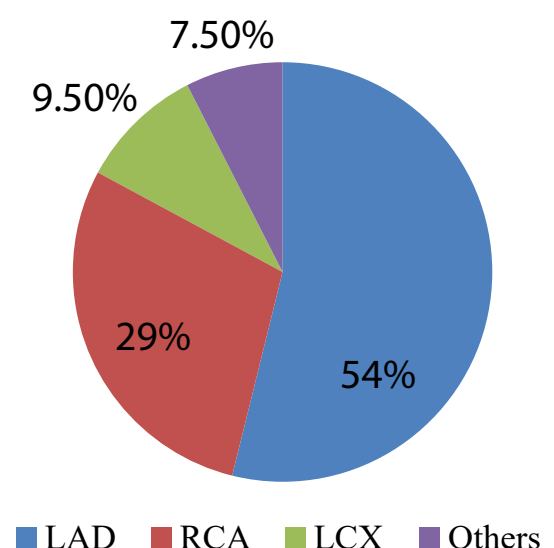

In all cases, wire could be crossed over the lesion. Only 4 cases out of 232 cases underwent plain balloon angioplasty due to the nature of lesion and vessels. While in all other cases, except for 1 patient with normal coronary arteries, DES was deployed. Thrombosuction because of excess thrombus burden was done in $45(19.5 \%)$ cases. TIMI III flow was reestablished in 97\% cases and TIMI II in 3\% cases.

Fig -3: Types of Coronary Intervention

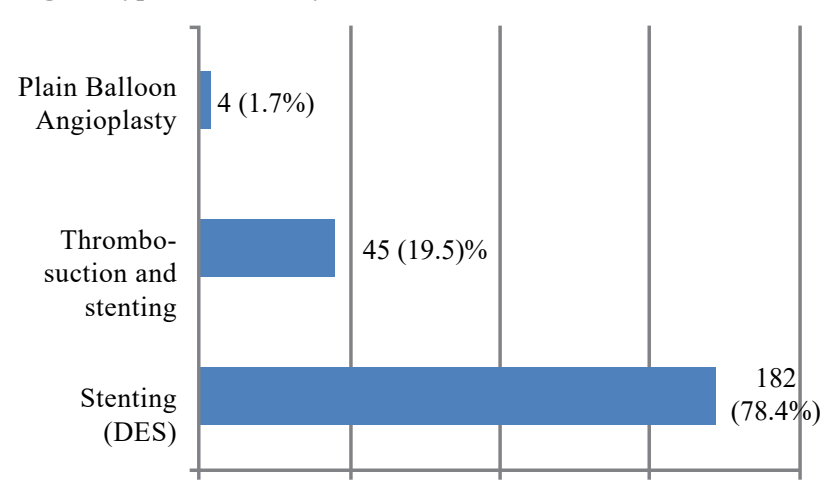

There were total of 8 deaths all during or after Primary PCI. 13 patients presented in cardiogenic shock, out of which 5 died. The commonest complication after PPCI was heart failure, occurring in 20 cases. The second most common complication was heart block requiring temporary pacemaker insertion in 18 cases. 1 patient needed a permanent pacemaker for persistent complete heart block. Post MI pericarditis/pericardial effusion developed in 11 patients, all of which resolved with conservative management. 3 patients developed access site complications in the forms of hematoma, AV fistula and pseudoaneurysm respectively. There were 4 cases of Transient ischemic stroke after PPCI, all the patients recovered their neurological function. VT/VF was encountered in 9 cases during hospital stay. 6 patients had developed LV apical clot in follow up, all had anterior wall MI. There were 2 cases of coronary artery dissection caused by guiding catheter which were managed immediately with stenting. 1 patient presented with subacute stent thrombosis in follow up. Acute Kidney Injury (Pre-renal and Contrast Induced Nephropathy) was seen in 11 cases $(4.7 \%)$ but none of the patients required hemodialysis after PPCI. Average hospital stay was 7.6 days. Average LVEF at discharge was $44.73 \%$.

Table 2: Complications and In-Hospital Mortality Rates After PCI

\begin{tabular}{|c|c|}
\hline Heart failure & 20 \\
\hline Heart block & 18 \\
\hline $\begin{array}{l}\text { Post MI pericarditis/ pericardial } \\
\text { effusion }\end{array}$ & 11 \\
\hline Ventricular arrhythmias & 9 \\
\hline LV clot & 6 \\
\hline TIA/stroke & 4 \\
\hline Access site complication & 3 \\
\hline Radial artery & 1 \\
\hline AV fistula & 1 \\
\hline Femoral artery & 4 \\
\hline Pseudoaneurysm & 1 \\
\hline Hematoma & 1 \\
\hline Bleeding (retroperitoneal) & 2 \\
\hline $\begin{array}{l}\text { Coronary Artery Dissection (iatro- } \\
\text { genic) }\end{array}$ & 2 \\
\hline Permanent Pacemaker Insertion & 1 \\
\hline Stent thrombosis (subacute) & 1 \\
\hline \multicolumn{2}{|l|}{ In hospital mortality } \\
\hline Primary PCI & 8 \\
\hline Cardiogenic shock & 5 \\
\hline Non-cardiogenic shock & 3 \\
\hline Elective PCI & 0 \\
\hline
\end{tabular}

\section{Discussion}

PCI was a therapeutic option far from reach to general population till recent past in our country. But now, with the development of health infrastructures, trained manpower and health awareness among the general population, it has become feasible for most of the patients in the country. In our study, all patients were taken for PPCI rather than 
thrombolysis because of the superiority in outcomes with PPCI. In this study, average age of patients was 57.39 years. This finding is similar to the previous studies done in our country ${ }^{9,10}$. About $12 \%$ of cases were below 40 years of age, youngest patient being 24 years of age.

As with other studies, STEMI was more common in males (74.5\%). The traditional cardiovascular risk factors like hypertension, diabetes and smoking were dominant in our country as well. The percentage of patients diagnosed as hypertensive was lower $(35 \%)$ than other studies in our country. The percentage of diabetes $(28.2 \%)$ was similar to other studies. While $50 \%$ of our patients were current or former smoker, this varied from $34 \%$ to $76.47 \%$ in other studies $9,10,11$. One of the major determinants of outcome in MI is the time interval between onset of symptom to revascularization. In our study, the average time of presentation was 17.5 hours after the symptom onset. While the average time for patients taken for PPCI was 7.6 hours. In the previous study, this was about 8 hours ${ }^{11}$.

Our study showed that nearly $34 \%$ of our patients presented after 12 hours of symptoms onset. The reasons for this may be due to delay in diagnosis, the time lost during referral from non-PCI capable centres, time delay in transport which is inevitable owing to the poor infrastructure and geographical condition of the country and lack of awareness in general population about the benefits of early revascularization in STEMI. Of these $34 \%$ patients, $21 \%$ patients underwent PPCI, as per recommendations in guidelines ${ }^{12}$.

Anterior wall STEMI was commonest accounting for $53 \%$ followed by Inferior wall, $41.81 \%$. 13 patients $(5.6 \%)$ had presented in cardiogenic shock. LAD was the commonest culprit vessel as in other studies. Multivessel disease was present in $64.6 \%$ cases, consistent with international data ${ }^{13}$.

Radial artery was preferred choice of vascular access for PPCI i.e nearly $85 \%$. This was in vast contrast to previous study performed in our centre in which only femoral access was used ${ }^{11}$. Radial access was associated with lower access site complications, more patient comfort after the procedure and early mobilization. Only 1 patient had developed AV fistula in radial group while 1 patient had groin site hematoma, 1 had femoral artery pseudoaneurysm and 2 had retroperitoneal bleed in femoral access group.

There were 8 mortalities, all in Primary PCI group. In-hospital mortality rates for patients presenting with and without cardiogenic shock were $38.46 \%$ and $1.59 \%$ respectively. The overall mortality rate was $3.98 \%$. The mortality rate of cardiogenic shock patients is comparable to the previous study done at SGNHC, Nepa ${ }^{19}$. The mortality rate in patients without cardiogenic shock and overall mortality rate are similar to the studies conducted in Nepal ${ }^{9,10,11}$, India ${ }^{14,15}$ and international registry ${ }^{16,17}$.

\section{Limitations}

There are few limitations of this study. First, it is a single centre retrospective study. And second is the lack of data on long term outcomes.

\section{Conclusion}

This study has reemphasized that PCI is effective in the management of STEMI cases in Nepal with improving mortality rates and decreasing complications. Minimizing the delayed presentation after the onset of symptoms should be one of the prime focuses for effective management of STEMI.

\section{Sources of funding: None}

Conflict of Interest: None

\section{References}

1. Cardiovascular diseases (CVDs) Fact sheet [Internet]. WHO. [Cited 2019 MARCH 3]. Available from https://www.who.int/news-room/fact-sheets/detail/ cardiovascular-diseases-(cvds)

2. Top ten causes of death, 2017 [Internet]. The Institute for Health Metrics and Evaluation (IHME).[Cited 2019 March 3] Available from

http://www.healthdata.org/nepal

3. Aude Marceau, Jean-Michel Samson, Nathalie Laflamme, Stéphane Rinfret. SHORT AND LONG-TERM MORTALITY AFTER STEMI VERSUS NON-STEMI: A SYSTEMATIC REVIEW AND META-ANALYSIS. Journal of the American College of CardiologyVolume 61, Issue 10 Supplement, March 2013DOI: 10.1016/S0735-1097(13)60097-2 https://doi.org/10.1016/S0735-1097(13)60097-2

4. Fox KA, Poole-Wilson P, Clayton TC, et al. 5-year outcome of an interventional strategy in non-ST-elevation acute coronary syndrome: the British Heart Foundation RITA 3 randomised trial.Lancet. 2005; 366:914-920. https://doi.org/10.1016/S0140-6736(05)67222-4

5. Cannon CP, Weintraub WS, Demopoulos LA, et al. TACTICS (Treat Angina with Aggrastat and Determine Cost of Therapy with an Invasive or Conservative Strategy)-Thrombolysis in Myocardial Infarction 18 Investigators. Comparison of early invasive and conservative strategies in patients with unstable coronary syndromes treated with the glycoprotein IIb/IIIa inhibitor tirofiban.N Engl J Med. 2001; 344:1879-1887. https://doi.org/10.1056/NEJM200106213442501

6. Lagerqvist B, Husted S, Kontny F, et al. Fast Revascularisation during InStability in Coronary artery disease (FRISC-II) Investigators. 5-year outcomes in the FRISC-II randomised trial of an invasive versus a noninvasive strategy in non-ST-elevation acute coronary syndrome: a follow-up study.Lancet. 2006; 368:998-1004 https://doi.org/10.1016/S0140-6736(06)69416-6

7. Fox KA, Clayton TC, Damman P, et al. FIR Collaboration. Long-term outcome of a routine versus selective invasive strategy in patients with non-ST-segment elevation acute coronary syndrome a meta-analysis of individual patient data.J Am Coll Cardiol. 2010; 55:2435-2445 https://doi.org/10.1016/j.jacc.2010.03.007.

8. Keeley EC, Boura JA, Grines CL. Primary angioplasty versus intravenous thrombolytic therapy for acute myocardial infarction: a quantitative review of 23 randomised trials. Lancet. 2003; 361:13 https://doi.org/10.1016/S0140-6736(03)12113-7

9. Adhikari CM, Bhatta YD, Malla R, et al. Outcomes of Primary Percutaneous Coronary Intervention at Shahid Gangalal National Heart Centre, Kathmandu, Nepal. Journal of Advances in Internal Medicine 2013;02(01):6-9. https://doi.org/10.3126/jaim.v2i1.7629

10. Dubey Laxman, Bhattacharya Rabindra, Guruprasad Sogunuu, Subramanyam Gangapatnam. (2013). Early Clinical 
Outcomes of Primary Percutaneous Coronary Intervention in Bharatpur, Nepal. Mædica. 8. 103-7.

11. Anil OM, Arun S, Rajesh N, et al. Primary percutaneous coronary intervention for the treatment of acute ST-segment elevated myocardial infarction: Initial single-center experience from Kathmandu, Nepal. J Clin Prev Cardiol 2018;7:132-6 https://doi.org/10.4103/JCPC.JCPC_15_18.

12. O'Gara PT, Kushner FG, Ascheim DD, et al. 2013 ACCF/ AHA guideline for the management of ST-elevation myocardial infarction: a report of the American College of Cardiology Foundation/American Heart Association Task Force on Practice Guidelines. Circulation. 2013;127:e362-e425 https://doi.org/10.1161/CIR.0b013e3182742cf6.

13. Park D, Clare RM, Schulte PJ, et al. Extent, Location, and Clinical Significance of Non-Infarct-Related Coronary Artery Disease Among Patients With ST-Elevation Myocardial Infarction. JAMA. 2014;312(19):2019-2027. doi:10.1001/ jama.2014.15095

https://doi.org/10.1001/jama.2014.15095
14. Subban V, Lakshmanan A, Victor SM, et al. Outcome of primary PCI - an Indian tertiary care center experience. Indian Heart J. 2014;66(1):25-30.

https://doi.org/10.1016/j.ihj.2013.12.036

15. Rishi Kumar Gupta, Simmi Manocha, Subrat Akhoury, Umesh Kohli. Clinical Characteristics and Outcomes of Percutaneous Coronary Intervention in Patients with STEMI: A Single-Center Experience. J Assoc Physicians India. 2019 Jan;67(1):40-43.

16. Eric D. Peterson, David Dai, Elizabeth R.et al. Contemporary Mortality Risk Prediction for Percutaneous Coronary Intervention: Results From 588,398 Procedures in the National Cardiovascular Data Registry,Journal of the American College of Cardiology, Volume 55, Issue 18,2010,Pages 1923-1932,ISSN 0735-1097,https://doi. org/10.1016/j.jacc.2010.02.005. https://doi.org/10.1016/j.jacc.2010.02.005

17. Menees DS, Peterson ED, Wang Y, Curtis JP, Messenger JC, Rumsfeld JS, et al. Door-to-Balloon Time and Mortality among Patients Undergoing Primary PCI. New England Journal of Medicine. 2013;369(10):901-9. https://doi.org/10.1056/NEJMoa1208200 